\title{
The TCE-RBV Framework for Information Systems Outsourcing: Empirical Testing using Survey Data in Japan
}

\author{
Seigo Matsuno*, Shin-ya Tagawa, Yasuo Uchida \\ Dept. of Business Administration, National Institute of Technology, Ube College, Ube, Yamaguchi 755-8555, Japan
}

Tsutomu Ito, Takao Ito

Graduate School of Engineering, Hiroshima University, Higashi-Hiroshima, Hiroshima 739-8527, Japan

*Corresponding author, E-mail: matsuno@ube-k.ac.jp

Tel: +81-836-35-4016, Fax: +81-836-35-4016

\begin{abstract}
This paper investigates the factors that influence the motives of make-or-buy decisions on information systems from the viewpoints of Transaction cost economics (TCE) and the resource-based view (RBV). Using our original questionnaire survey data carried out in 2007 targeting Japanese firms, we analyze the relationships between the recognition related to the role of their information systems and the pattern of their make-or-buy decisions. As a result, we make it clear that there are two cases in which TCE-motive and RBV-motive are complement or contradictory each other. And in latter case, TCE-motive tends to dominate over RBV-motive. Finally, the implications for theory and practice are discussed.
\end{abstract}

Keywords: Information systems outsourcing, Make-or-buy decisions, Transaction cost economics, Resource-based view

\section{Introduction}

Up to now, two influential perspectives of outsourcing, that is, Transaction cost economics (TCE) and the resource-based view (RBV) have been both making a valuable contribution to understanding and explaining the complexities of outsourcing. However, the discussion has treated TCE and RBV as independent approaches to the outsourcing decisions. This paper investigates the factors that influence the motives of make-or-buy decisions on information systems (IS) from the viewpoints of TCE and the RBV.

This paper is organized as follows. In Section 2, we briefly review some previous arguments of the IS outsourcing. After reviewing the relevant literature on the IS outsourcing, we analyze the relationships between the recognition related to the role of their information systems and the pattern of their make-orbuy decisions. The TCE-RBV framework is tested empirically by using our original questionnaire survey data targeting Japanese firms in Section 3. In Section 4, 
we discuss the implications derived from the results of the statistical testing. Finally, in Section 5 we conclude by a summary of this paper.

\section{Literature review on IS outsourcing}

\subsection{Transaction-based perspective}

TCE posits that organizations prefer insourcing when the market costs are higher than internal governance costs [1]. Markets generally lead to smaller production costs, because of economies of scale obtained by suppliers and/or vendors. However, markets lead to higher transaction costs arising from three principal attributes of transactions: asset specificity, uncertainty, and frequency [2].

Asset specificity for the IS outsourcing has two aspects; for business of a client company supported by the developed information systems, and for technologies which external vendors utilize. If the business that a client company outsources is unusual, external vendors have to be familiar with the business so that the asset specificity will occur and increase on mainly human resources. Similarly, if technology used by external vendors is very specific, it will be difficult to use the information systems for other purposes on the client company. Due to the investment to these unusual assets, the transaction costs would increase.

Hence, if it is necessary to reduce the risk of opportunism resulted from asset specificity and to restrict the increase of transaction costs, insourcing or quasi-outsourcing would be selected.

\subsection{Resource-based perspective}

The RBV of the firm posits that organizations prefer insourcing when a resource or capability is strategic so as to enable them to sustain competitive advantage [3]. It builds upon four properties of a strategic resource: economic value, rareness, imperfect imitability, and non-substitutability. The RBV is important to the study of the IS outsourcing, as superior performance achieved in the IS activities related to external vendors would explain why such activities are performed internally.

Thus understanding of managerial resources as an advantage for the company is called "core competencies" in general today. Prahalad and Hamel (1990) defined the core competence as "a combination of technologies and production skills which is based on the company's infinite product lines" [4]. This concept is understood more broadly today and is recognized as their own resources and abilities, which are hard to be imitated and implemented by other companies, as a source of the company's sustainable competitive advantage.

From the viewpoint of the RBV, competitive advantage of organizations can only be achieved through a focus on core competencies, the management of organizations have chosen to concentrate on what an organization does better than anyone else while outsourcing the rest.

\subsection{The TCE-RBV Framework}

The large number of studies of the IS outsourcing was published in the past [5]. Especially, in the previous study on the two patterns of the IS outsourcing, some focus on factors of the influence on its selection. For instance, Barthelemy and Geyer (2005) classify the factors of the influence on the choice of either conventional outsourcing or quasi-outsourcing into internal and external factors [6]. They focus on testing some hypotheses which are suggested based on the TCE approach, but they do not refer to the RBV arguments.

TCE and the RBV approach are treated as independent argument so far, but each theoretical perspective alone cannot fully describe the phenomena of the IS outsourcing. Then there is a growing bodies of research on the recognition that the TCE and the RBV are complementary one another [7].

McIvor (2009) integrated TCE and the RBV perspectives into a framework specifically assessing the outsourcing decisions [8]. The TCE dimension of this framework focuses upon the potential for opportunism in any outsourcing decision. The RBV dimension focuses upon a firm's resource position against potential suppliers or competitors. This conceptual framework (see Fig. 1) suggests that for an activity in which the firm has a weak resource position or capability, and the potential for opportunism is low, outsourcing is the best option. In the opposite case, where a firm enjoys strong resource position and potential for opportunism is high, insourcing is the best answer. This framework implies not only complementary but also contradictory prescriptions of the RBV and TCE in outsourcing decisions due to the inherent conflicts between the two theories [9]. 


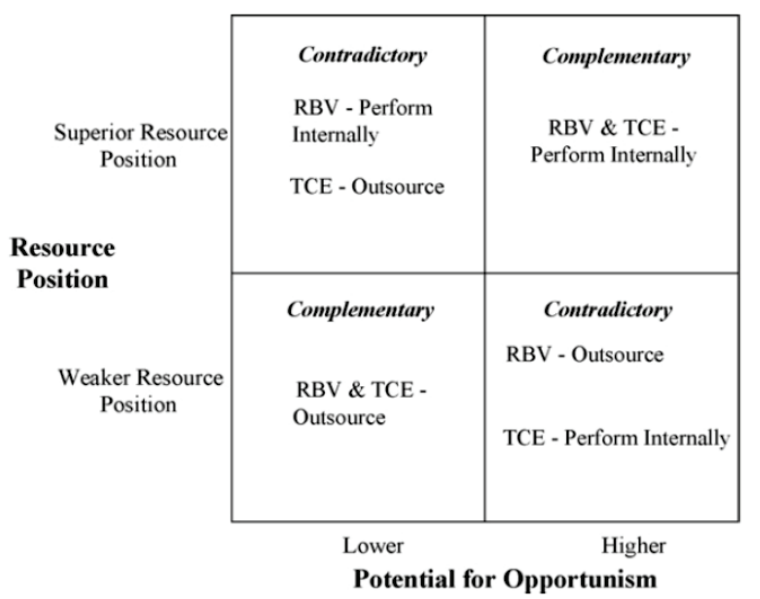

Fig. 1. The TCE-RBV Framework. (Adapted from McIvor, 2009.)

\section{Data and Method}

\subsection{Data collection}

We conducted a mail questionnaire survey from July to September 2007 with the research objective of investigating "the current state and issues in IS outsourcing and inter-firm collaboration". Since ordinarily the implementation of IS outsourcing is likely to be affected by a firm size, we targeted Japanese firms with 500 or more employees in this survey. The number of valid response rate obtained from randomly sampled firms was $25.9 \%$, but detailed results are omitted here.

\subsection{Constructs variables and operationalization}

In this study, it is postulated that both 'TCE-motive' attaching importance to the logic of TCE and 'RBVmotive' attaching importance to the logic of the RBV affect make-or-buy decision making on information systems. And we assume that these two constructs consist of each four question items shown in Table 1 . Each score (6-point scale) obtained directly from each question item is regarded as an interval scale.

Here, we omit exploratory factor analysis process for examining the validity of the assumed constructs variables and use the value obtained by dividing the total of the values of the items pertaining to each construct variable by the number of items. The reliability of the measurements was calculated using the Cronbach's $\alpha$.
Table 1. Status of the recognition related to the roles of ICT and information systems

\begin{tabular}{cc}
\hline Construct & \multicolumn{1}{c}{ Items } \\
\hline TCE-motive & 1. Even if the company's own information \\
$(\alpha=0.73)$ & systems are outsourced, it isn't expected \\
& to reduce the cost concerning them. \\
& $\begin{array}{l}\text { 2. When the company's own information } \\
\text { systems are outsourced, it isn't expected } \\
\text { to accumulate skills and know-how } \\
\text { concerning them. }\end{array}$
\end{tabular}

3. When the company's own information systems are outsourced, there is a risk that it would be dependent excessively on a specific vendor.

4. When the company's own information systems are outsourced, it isn't possible to correspond to internal users' needs rapidly.

RBV-motive 1. ICT is very important to reduce the cost $(\alpha=0.80) \quad$ of the company's products and services.

2. ICT is very important to improve the quality of the company's products and services.

3. ICT is closely related to and operated integrally with the execution of the company's core business.

4. ICT is an important infrastructure which supports the execution of the company's core business.

Note: Each item is measured by 6-point scale. $1=$ It does not apply at all. $6=$ It applies fully.

Then, we classified sample data into 4 groups based on the average value of each construct variable. For example, LOSR (Lower potential for Opportunism and Superior Resource position) group means that the average value of TCE-motive is lower than the average value of the whole and the average value of RBVmotive is higher than the average value of the whole. On the contrary, HOWR (Higher potential for Opportunism and Weaker Resource position) group means that the average value of TCE-motive is higher and the average value of RBV-motive is lower than each average value of the whole.

\section{Analysis and discussion}

We conducted a chi-squared test between the 4 groups mentioned above and the IS sourcing pattern (insourcing or outsourcing). Such a contingency table is shown in Table 2. The result was significant $\left(\chi^{2}(3)=\right.$ $11.96, p=0.01$, Cramer's $V=0.26$, power $=0.84$ ) and therefore the two variables are not independent. The 
evaluation of effect size was medium degree and power of the test was a desirable level sufficiently.

In Table 3, from the multiple comparison testing among 4 groups (adjusted $p$-value is based on Benjamini and Hochberg, 1995) [10], we found out the significant difference between each of HOSR-LOSR, HOSR-LOWR, LOSR-HOWR, LOWR-HOWR $\left(\chi^{2}(1)\right.$ $=4.92, p=0.05 ; \chi^{2}(1)=4.55, p=0.05 ; \chi^{2}(1)=5.34, p=$ $0.05 ; \chi^{2}(1)=5.00, p=0.05$, respectively).

Table 2. Contingency table of the relation between the 4 groups and the IS sourcing pattern

\begin{tabular}{ccc}
\multicolumn{3}{c}{ groups and the IS sourcing pattern } \\
\hline & Outsourcing & Insourcing \\
\hline \multirow{2}{*}{ HOSR } & 28 & 31 \\
& $(0.47)$ & $(0.53)$ \\
LOSR & 32 & 13 \\
& $(0.71)$ & $(0.29)$ \\
LOWR & 31 & 13 \\
& $(0.70)$ & $(0.30)$ \\
HOWR & 14 & 19 \\
& $(0.42)$ & $(0.58)$ \\
\hline
\end{tabular}

Note: The numerical value in each parenthesis is the relative frequency in each row.

Table 3. Multiple comparison test among 4 groups

\begin{tabular}{cccc}
\hline & $\chi^{2}$ & $d f$ & adj. $p$ \\
\hline HOSR - LOSR & 4.92 & 1 & 0.05 \\
HOSR - LOWR & 4.55 & 1 & 0.05 \\
HOSR - HOWR & 0.06 & 1 & 0.97 \\
LOSR - LOWR & 0.00 & 1 & 1.00 \\
LOSR - HOWR & 5.34 & 1 & 0.05 \\
LOWR - HOWR & 5.00 & 1 & 0.05 \\
\hline
\end{tabular}

In light of the above analysis, the percentage of IS insourcing is high by HOSR group, and the percentage of IS outsourcing is high by LOWR group conversely. This means that TCE-motive and RBV-motive are complement mutually. On the other hand, the percentage of IS outsourcing is high by LOSR group, and the percentage of IS insourcing is high by HOWR group. Therefore, when TCE-motive and RBV-motive are contradictory each other, TCE-motive tends to relatively dominate over RBV-motive.

\section{Concluding remarks}

This paper investigates the factors that influence the motives of make-or-buy decisions on information systems from the viewpoints of TCE and the RBV. We empirically test the TCE-RBV framework by using our original questionnaire survey data targeting Japanese firms. As a result, we made it clear that there were two cases in which TCE-motive and RBV-motive were complement or contradictory each other. And in latter case, TCE-motive tends to dominate over RBV-motive.

\section{Acknowledgments}

This research was partly supported by the Japan Society for the Promotion of Science, Grant-in-Aid for Scientific Research (C) 16K03843 and authors would like to thank the organization.

\section{References}

1. R. Coase, The nature of the firm, Economica, 4(16) (1937), 386-405.

2. O. Williamson, Markets and Hierarchy: Analysis and Antitrust Implications (Free Press, 1975).

3. J. Barney, Firm resources and sustained competitive advantage, J. Management, 17(1) (1991), 99-120.

4. C. Prahalad and G. Hamel, The core competence of the corporation, Harvard Business Review, 68(3) (1990), 79 91.

5. S. Matsuno, T. Ito, and Z. Xia, Determinants of information systems outsourcing: An empirical investigation in Japan, Artificial Life and Robotics, 14(3) (2009), 337-341.

6. J. Barthelemy and D. Geyer, An empirical investigation of IT outsourcing versus quasi-outsourcing in France and Germany, Information \& Management, 42(4) (2005), 533-542.

7. O. Williamson, Strategy research: Governance and competence perspectives, Strategic Management J., 20 (1999), 1087-1108.

8. R. McIvor, How the transaction cost and resource-based theories of the firm inform outsourcing evaluation, $J$. Operations Management, 27(1) (2009), 45-63.

9. B. Brewer, C. Wallin, and B. Ashenbaum, Outsourcing the procurement function: Do actions and results align with theory?, J. Purchasing \& Supply Management, 20 (2014), 186-194.

10. Y. Benjamini and Y. Hochberg, Controlling the false discovery rate: A practical and powerful approach to multiple testing, J. Royal Statistical Society: Ser. B, 57(1) (1995), 289-300. 